\title{
Research on Heritage Information Establishment of Cultural Relics Based on the Three-dimensional Photography
}

\author{
Bin Guan \\ School of Art \\ Hubei University of Education
}

\begin{abstract}
Three-dimensional photographic technique is used to establish the three-dimensional database system of cultural relics. Information management and application of the cultural relics can be realized. Multiple functions such as collection, analysis and communication of resources of cultural relics can be implemented. The protection of cultural relics is enhanced to a new level. Realizing open search of the cultural relics data, exchanging international cultural, enriching people's spiritual life, propagating history sound, has a certain historical significance and social economic value.
\end{abstract}

Keywords-three-dimensional photography; informatization; cultural relics protection

\section{INTRODUCTION}

The science and technology develops rapidly in modern times. With the increasingly high living standards, people pay more and more attention to learning knowledge about heritage and have increasingly strong consciousness to ardently love and protect cultural relics. The report of the 18th National Congress of the CPC proposes building a moderately well-off society in an all-round way in 2020 requires "the sharp increase of informatization level". "Informatization" develops in the unprecedented speed and has broken through technological means, extending to the field of heritage conservation. The informatization of cultural relics is also practiced and explored, advancing steadily. Recently, the official website of the State Bureau of Cultural Relics releases the policy of the Three-year Action Plan of "Internet plus Chinese Civilization" jointly compiled by the State Bureau of Cultural Relics, National Development and Reform Commission, Ministry of Science and Technology, Ministry of Industry and Information Technology and Ministry of Finance.

Hubei province has a profound historical accumulation and abundant cultural relics. In the 3rd national archaeological survey, Hubei province has 36,473 immovable sites of cultural relics, 197 museums at all levels, exceeding 1.78 million sets of cultural relics in the collection of cultural institution and specimen, referring to a province with lots of cultural relics in

Fund project: (This paper is one of the achievements of youth fund project for the research on humanities and social sciences of the Education Department in Hubei province in 2016, Research on the Application of 3D Photography in the Construction of Digital Museum, project approval number “16Q272”). our country. Although the information construction of cultural relics in our province has preliminary results, it is still at the initial stage. In 2017, in order to implement the document about the informatization of cultural relics, the Three-year Action Plan of Internet plus Chinese Civilization, relevant units of the Cultural Relics Bureau strengthen the cooperation with universities and enterprises, using modern science and technology to roundly improve the informatization level of cultural relics to promote Hubei as a province with lots of cultural relics. In 2016, the Government of Xianfeng County in Hubei Province adopted the Strategies for the Protection and Improvement of the Historic Site of Tangya Tusi in Xianfeng written by Guan Bin in Hubei University of Education, and organized experts to research the policy about 3D virtual modeling on Tangya Tusi. According to the actual state of the information construction of cultural relic of Tangya Tusi in Xianfeng County of Hubei Province and the development tendency of the informatization of cultural relics, this paper describes the advantages of 3D photography in the information construction of cultural relics and the plans, letting people know more about 3D photography in the information construction of cultural relics, in order o improve the information construction of cultural relics, which will have social benefit and economic benefit.

\section{THE DEVELOPMENT OF INFORMATION-BASED}

\section{PROTECTION OF CULTURAL RELICS AT HOME AND ABROAD}

The information-based protection of cultural relics has begun in developed countries. In 1986, the Art Union in France collected more than 500,000 cultural relics of fine arts through digital technology and conducted the digital virtual reconstruction of Louvre, so that 120,000 cultural relics in the collection of Louvre reappear on the internet; at the close of the 20th century, the 3D data acquisition was conducted for the Giant Buddha in kamakura period in Japan and the Buddha received virtual repair and reconstruction; America IBM Tokyo Institute and Japan National Museum of Ethnology formulated the famous "Global Digital Museum Plan". Similarly, the preservation of cultural relics at homes also develops gradually with scientific and technological progress. In 2000, the National Palace Museum in Beijing realized "Digital Imperial Palace" through 3D imaging technique; the 
digital museum of Shandong University conducts the 3D information-based collection of more than 5,000 cultural relics.

\section{THE METHODS FOR THE INFORMATION-BASED CONSTRUCTION OF CULTURAL RELICS}

The information-based construction of cultural relics is to establish the data file of cultural relics through informationbased means like 3D collection technology, web service technology and database technology, in order to realize the information-based preservation, display, search, communication, analysis and management of cultural relics. The information-based construction of cultural relics must be under the leadership of the government, which formulate the unified code standards of information collection, collecting record and text description of cultural relics. Museums at county level, city level and provincial level shall establish the unified information retrieval system of cultural relics and let every cultural relic have detailed "Identity Certificate"; the electronic map about the address of immovable large cultural relics shall be established.

3D information collection is important in establishing the $3 \mathrm{D}$ informatization of cultural relics. 3D model can accurately record the all-round information of cultural relics and publicize cultural relics through vivid effect for people to appreciate, analyze protect cultural relics, becoming a comprehensive platform for management departments of cultural relics and the masses to understand cultural relics. For example, large 3D spatial database of cultural relics has been established in Guizhou Province, becoming an important part of the management, publicity and protection of cultural relics in Guizhou; therefore, the 3D information-based collection of cultural relics is the basis to construct the informatization of cultural relics. The methods are as follows:

\section{A. Conduct Modeling of Cultural Relics through 3D Software}

3D modeling software like 3DMAX and MAYA are used to conduct the $3 \mathrm{D}$ modeling of cultural relics. HD digital camera is used to conduct texture mapping of the surface of cultural relics. But they are seldom used in the modeling of cultural relics because the steps are complicated, it requires professionals, and cannot restore cultural relics in the samesize ratio and errors exist.

\section{B. Build 3D Model of Cultural Relics through Serial Image Technology}

The rapid 3D reconstruction of cultural relics based on $2 \mathrm{D}$ images is easy and free from the influence of time and space, with low cost, high degree of automation and efficiency. But in the 3D model of cultural relics through digitalization, the data acquired is incomplete and the deficiency of information about cultural relics is serious, failing to meet the needs in $3 \mathrm{D}$ reconstruction of cultural relics.

\section{Conduct the 3D Reconstruction of Cultural Relics through Laser Scanning}

In modern times, the laser scanner technique has been advanced. The model of cultural relics established by laser scanner has high accuracy and efficiency. However, the working principle of laser scanning is to obtain 3D data through contacting laser with the cultural relics. The direct contact of light is harmful to cultural relics; laser scanner fails to scan the dark part or highly reflective part of cultural relics, so developing power must be painted on these parts before laser scanning, while the developing power will cause the direct pollution damage to cultural relics; when scanning some cultural relics with complex structure, artificial target points must be added to the surface of cultural relics, which will directly damage it. These steps are not allowed in the 3D modeling of cultural relics.

\section{Conduct 3D Reconstruction of Cultural Relics through 3D Techniques for Photography}

3D photography refers to the 3D modeling system based on Photoscanshop computer software technology and photography. The pictures of cultural relics are obtained through photography and will conduct automatic synthesis through software, with fast speed, low cost and high accuracy. The collecting technology is tower over the laser scanning.

\section{The AdVANTAges OF APPLYING 3D PHOTOGRAPHY IN THE INFORMATION-BASED CONSTRUCTION OF CULTURAL RELICS}

$3 \mathrm{D}$ photography means conducting the $3 \mathrm{D}$ visual collection of the data of cultural relics through using the minimum intervention means rapidly and accurately to present the $3 \mathrm{D}$ characteristics of cultural relics intuitively. The advantages are as follows:

\section{A. Rapid 3D Digital Collection of the Data of Cultural Relics}

People can collect the information of cultural relics through digital imaging equipment at any time and conduct the automatic 3D integration of the data collected through software, turning images into 3D digital information at will, instead of conducting the 3D integration of images through professional photographic equipment, photographers and 3D software. It reduces steps, procedures and equipment, and people can show 3D cultural relics at will.

\section{B. Show the Overall Cultural Relics}

At present, most of the information-based display of cultural relics focuses on single images and written records. The information displayed is incomplete and large quantities of high quality images consume network resources. It is difficult and a waste of time for people to browse. The 3D digital display of cultural relics through 3D photography can roundly show details of cultural relics and put them in the original environment, showing "experimental cultural relics". Audiences truly feel the overall effect of cultural relics in the virtue $3 \mathrm{D}$ space and understand the historical functions of them. It reaches the display and fidelity effects which cannot be achieved by the previous informatization and gives full play to the role of precious cultural relics in education on history.

\section{Virtual Repair and Reappearance of Cultural Relics}

Cultural relics are precious treasures left by history for people, but many of them suffer from irreversible damage 
because of the erosion of natural weathering, fire accidents and people's behaviors in historical development. It's impossible for us to restore its original appearance. 3D photography can record the $3 \mathrm{D}$ data of cultural relics preserved in the computer and conduct the virtual reconstruction of the damaged parts of cultural relics, so that audiences can feel the glory days of cultural relics. If errors exist in the reconstruction, we can correct it at any time, avoiding the wrong reconstruction because of the insufficient information.

\section{Develop the Historical and Economic Values of Cultural Relics with Zero Damage}

The preservation and development of the informatization of cultural relics are conflicting. The traditional laser scanning more or less causes light pollution for cultural relics in collecting the 3D data of them. With the development of contactless 3D digital photography, the problem will be solved. 3D photography establishes 3D digital display of cultural relics with the minimum damage, vigorously developing the cultural and economic value of cultural relics with zero damage. 3D photography avails the protection and inheritance of cultural relics and the development of 3D immersive and integral industry chain of virtual reality, forming the corresponding 3D films, digital museums, cartoon and games to promote the development of public cultural undertakings about cultural relics. Meanwhile, it turns the protecting force of cultural relics into the cultural productivity to produce the cultural and economic benefit and further stimulate people's enthusiasm in inheriting and protecting cultural relics.

The 3D database system of cultural relics established through 3D photography conducts the unified informationbased management and application of cultural relics and realizes the collection, analysis and communication of cultural relics, further improving the preservation of cultural relics. The open data query of cultural relics and the internationalization of cultural exchange about cultural relics can enrich people's spiritual life and spread the voice of history, having historical significance, social and economic value.

\section{THE SCHEMES FOR 3D INFORMATIZATION OF CUltural Relics}

\section{A. Data Acquisition}

Cultural relics have regular shapes and irregular shapes. The acquisition of data of cultural relics with regular shapes is easy, depending on the light on the cultural relics. Uniform light cannot be used because the contents of pictorial information of cultural relics with regular shape under uniform light are the same, and the software cannot recognize camera stand. Therefore, we shall use the light of 45 degrees to improve the discrimination degree of camera stand of computer software, or it easily forms the wrong positioning of single camera stand of software as shown in "Fig. 1".

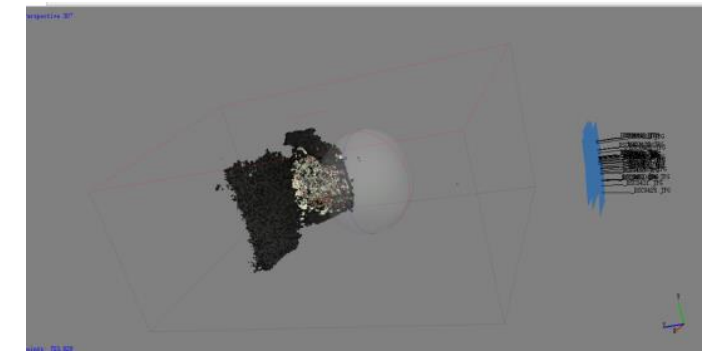

Fig. 1. The wrong positioning of single camera stand of software.

The acquisition of information about the surface of cultural relics with irregular shapes is different, especially when the surface structure of cultural relics is complicated and has defects and dark color. In order to accurately obtain the information about the surface of cultural relics, we must position the camera stand accurately. The distribution of camera stand must change uniformly according to the structure of cultural relics, keeping on the same coordinate system. And then the data of cultural relics will be obtained under the same requirement for time, color temperature and technical parameters. The data acquisition includes three steps:

1) Previous preparation: First arrange light for cultural relics, and adjust the color temperature of light source after determining the location of light source, stabilize the color temperature of light source in about $4500 \mathrm{~K}$, and then determine the shooting position and trace, guaranteeing at least $20 \%$ of overlapping exists for each photo.

2) Shooting: The resolution of photos is important in shooting. In order to guarantee the focus is clear, we must realize steady shooting through tripod or shooting track instead of using hand-hold cameras. The data must be collected when the camera is controlled by the computer, because computer screen can be used to better observe the actual effect after shooting, convenient for us to timely adjust the condition of shooting site.

3) Selection of photos: The natural shaking of camera and human factor in shooting will cause the repeat and deficiency of photos, which will obstruct 3D modeling, so we need to select photos through leak filling.

\section{B. Data Adjustment}

Strict color management and size adjustment are required for photos shot by cameras because of color temperature, exposure and unstable shooting. Professional color management system can restore the color of each photo and the size also meets corresponding requirements, so that the effect and speed of 3D synthesis in the future will not be influenced.

\section{3D Modeling}

Models established by 3D photography depends on the software Photoscan to automatically complete four steps of point cloud modeling, triangular mesh modeling and 3D surface modeling and 3D entity render. The data of modeling must be adjusted uniformly in the process, with a convenient 
and rapid operation, saving manpower, material resources and time in as shown in "Fig. 2".

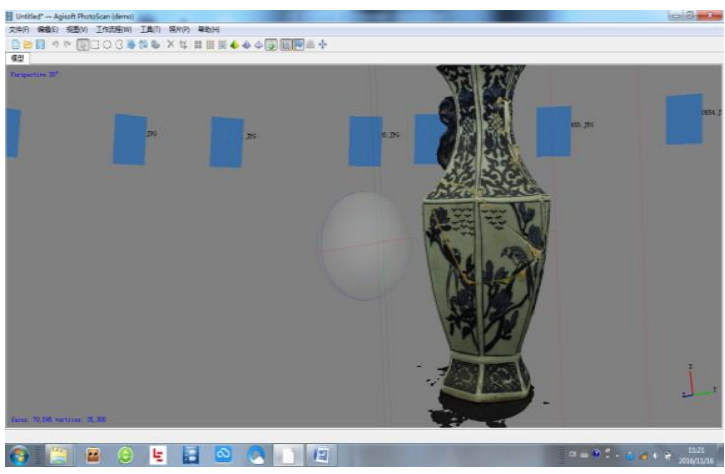

Fig. 2. 3D Modeling.

\section{The Design of 3D Information Database of Cultural Relics}

The 3D information of cultural relics has high accuracy and a large quantity of data. The processing of the numerous data in database processing easily causes system breakdown. In processing the mass information, we often use folder to sort the data and complete database retrieval and establish the indexed file, in order to find out the result rapidly.

\section{THE PROBLEMS IN THE 3D INFORMATIZATION OF Cultural Relics}

The following problems exist in the 3D information-based construction of cultural relics finished by 3D photography: First, the problem is color rendition. When the data of the surface of cultural relics is collected by digital cameras, the photos shot cannot completely restore the color on the surface of cultural relics because of the differences in light, shooting angle, shooting time and shooting equipment, so the professional team of color management is required to restore the color before the 3D software composition. Second, although the 3D informatization of cultural relics can be open to the public, it does not mean the information of all the cultural relics can be shared whenever and wherever possible. We must guarantee the privacy right of some cultural relics and release the information of cultural relics in different stages, levels, fields and regions, ensuring the safety of cultural relics as well as the social education sense of cultural relics. Third, with the development of science and technology, the image information has become the intangible resources derived from actual resources. The 3D information of cultural relics will be revealed in the process of transmission and application. The protection of intellectual property of cultural relics is the priority among priorities. Fourth, the $3 \mathrm{D}$ informatization of cultural relics is the need of historical development. We shoulder heavy responsibilities. Nowadays, the talents that roundly understand the knowledge about cultural relics and computer are rare, so the education sectors shall train more professionals, in order to comprehensively realize the $3 \mathrm{D}$ informatization of cultural relics as early as possible.

\section{CONCLUSION}

By using 3D photography to acquire the information of cultural relics, we can preserve and develop the resources of cultural relics with the minimum damage to them, solving the main contradiction between the preservation and development of historical relics. The large-scale utilization of 3D photography to establish the informatization of cultural relics conforms to the policies of the Party and the Nation in the preservation of cultural relics, at the same time is the inevitable choice to preserve and develop cultural relics in the information-based era.

\section{REFERENCES}

[1] Levoy M, Pulli K,Curless B,et al.The digital michelangelo project: 3Dscanning of large statues[C]// Siggraph 2000. ACM Press,2000.

[2] Fabio B,Stefano B,Giovanna D S.From 3 D reconstruction to virtual reality: A complete methodology for digital archaeological exhibition [J].J Cult Herit, 2010.

[3] Lou Fangji, Yang Guangbin, Wang Maoyang, Liu Tiancai. Research on the Construction of Heritage Space Database in Guizhou Province [J], Journal of Guizhou Normal University (Natural Sciences Edition), 2015(10)

[4] Wang Zhaoping, Xue Li. Empirical Research on the Interaction between the Informatization of Compound System and Cultural Industry [J], Science and Technology Management Research, 2010(9)

[5] Li Xinyue. The Development and Application of Information Technology in Heritage Conservation in Museums [J], Jiangsu Science and Technology Information, 2015(2)

[6] Zhao Dong. Research on the Protection and Development of Historical and Cultural Resources under Digital Subsistence [D], Shandong: Shandong University, 2014 